\title{
Hits, leads and drugs against malaria through diversity-oriented synthesis
}

Malaria is a devastating infectious disease and approximately half the world's population is at risk. Since vaccination is not yet available, small-molecule-based medicines are currently the best option for the treatment of patients suffering from malaria and combating the spread of infection. Development of resistance against existing drugs has created a need for new types of small molecules to be screened against Plasmodium falciparum, the etiological agent of malaria. The advent of diversity-oriented synthesis has enabled access to novel chemical structures. Evaluation of diversity-oriented synthesis compounds in phenotypic assays for growth inhibition of $P$. falciparum has resulted in novel hits, leads and even investigational drugs against malaria.

Malaria is one of the most threatening diseases worldwide with approximately 3.3 billion people at risk which is approximately half the world's population [101]. In 2010 it was estimated that malaria afflected approximately 216 million people, resulting in nearly 0.65 million deaths, mostly among African children. Several species of Plasmodium can infect humans, with Plasmodium falciparum being the most serious and fatal type of malaria infection. Plasmodium vivax, Plasmodium ovale, Plasmodium malariae, and Plasmodium knowlesi to a lesser extent, can cause acute illness, but the mortality rate among these strains is low [1].

Efforts to eradicate this global threat have been problematic due to technical challenges, as well as economic, financial and institutional hurdles. Malaria is prevalent in underdeveloped nations with poor infrastructures, high population densities, and insufficient healthcare funding, which add more hurdles to the efforts of eradicating malaria [2].

Ideally preventing the spread of the disease with vaccines is the most effective path forward. Recent advancements with vaccines are promising, but it is unlikely that vaccines will be readily available in the immediate future [3]. In addition, genetic modifications of the mosquito which alter lifespan, function and paratransgenesis approaches are also attractive strategies [4-6]. However, as is the case for vaccines, these strategies will require more research before they can be implemented in the field. Thus, in the interim, the most effective tools for combating this disease are strategies to kill malaria through killing the mosquito, population suppressing strategies [7,102], using insecticide-treated bed nets, indoor residual spraying, and chemotherapy approaches. Chemotherapy is still most effective tool in combating this disease and the focus of this review. A major impediment in the use of chemotherapy in infectious diseases is the emergence of resistance $[8,9]$. Drug-resistant parasite has led to the re-emergence of malaria in many parts of the world where the disease had been previously eradicated [10]. In order to combat the spread of resistance there is an urgent need to discover new antimalarials with novel mechanisms of actions, particularly as combination therapies with different targets are increasingly being used to lessen the rate of resistance.

\section{Drug discovery against malaria}

The search for novel antimalarial compounds is centuries old and several drugs have emerged to effectively treat the disease. However, no new class of drugs has been introduced into clinical practice since 1996 (FIGURE I).

The emergence of parasite resistance to current drug regimens underscores the need for new drugs that act by novel mechanisms (i.e., through new targets). Identification and validation of novel targets for the development of new drugs will help in the fight against drug resistance in malaria. Equally important is the development of new chemical matter since structurally unique drugs are more likely to have unique biological targets. Globally it is estimated that 6-8 million compounds have been screened against malaria either by phenotypic assay or via target-based screening approaches through academic and industrial efforts. To date, such screens have been limited to identifying compounds that inhibit the growth of
Sivaraman Dandapani, Eamon Comer, Jeremy $\mathbf{R}$ Duvall \& Benito Munoz*

Chemical Biology Platform, Broad Institute, 7 Cambridge Center, Cambridge, MA 02142, USA

*Author for correspondence E-mail: bmunoz@broadinstitute.org 


\section{Key Terms}

Phenotypic assays: Screen used to identify substances such as small molecules, peptides, or RNAi that alter the phenotype of a cell in a desired manner.

\section{Diversity-oriented}

synthesis: Strategy for access to molecular libraries with high skeletal diversity.

Chemical complexity: As measured by $\mathrm{Fsp}^{3}$ content and the numbers of stereogenetic centers.

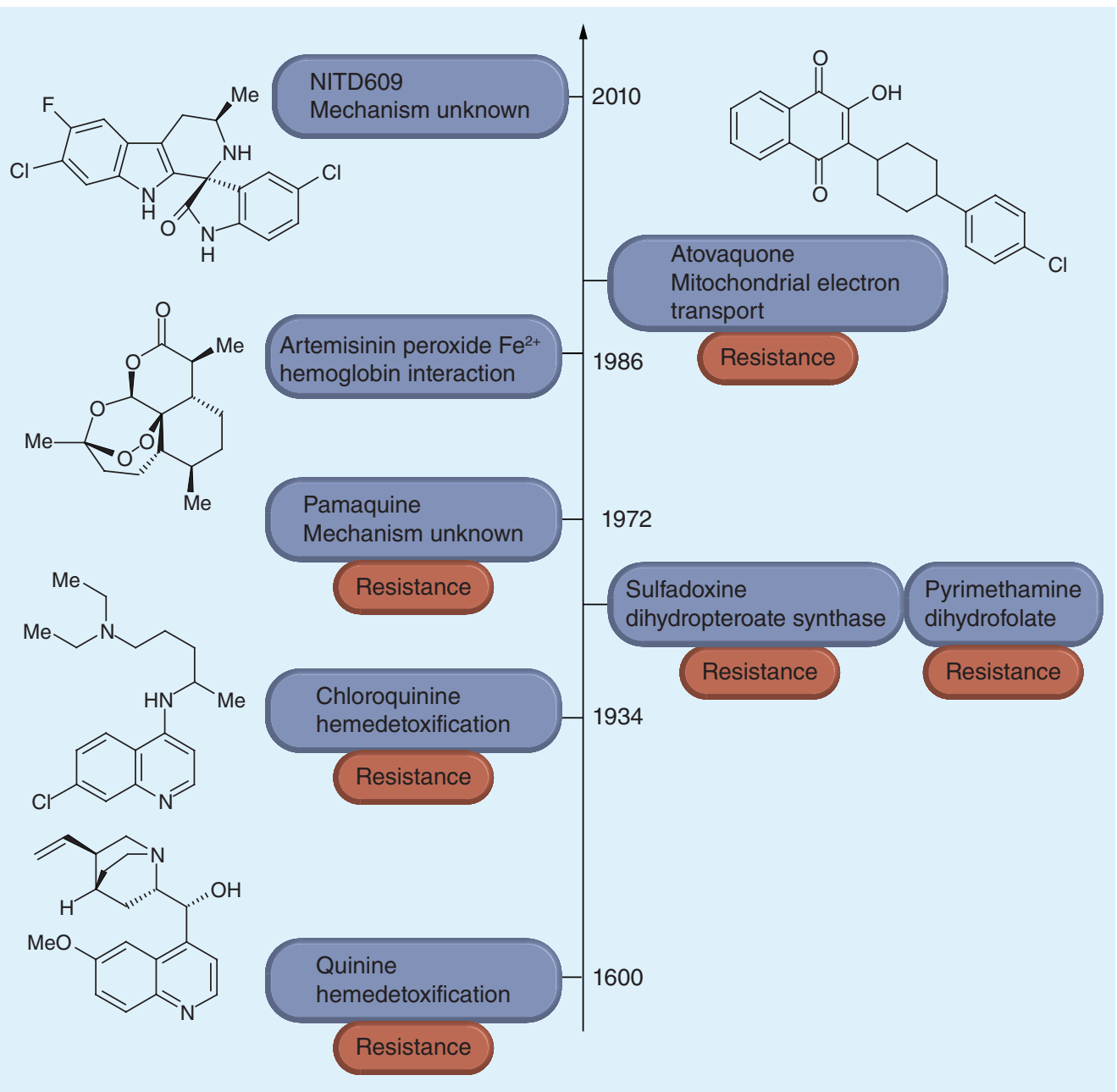

Figure 1. Timeline of drugs against malaria with new mechanism of action.

the parasite in the blood stage of the infection. To complement strategies that inhibit the blood stage, recent attention has shifted to inhibiting the liver stage of the infection, and a number of hits from these early screenings have been reported in the literature $[11,12]$. However, this review will focus on compounds that inhibit the blood stage of the infection for which the approximately 6-8 million compounds screened have been directed against. For example, GSK screened 2 million compounds and have made these hits available to the scientific community [13]. Genomic Institute of the Novartis Research Foundation reported the screening results from 1.7 million compounds [14]. St. Jude Hospital initiated a similar screening effort with 300,000 compounds [15]. Even after all these large-scale screening initiatives, it has been estimated that currently there are fewer than 30 distinct small-molecule scaffolds with reasonable in vivo activity against $P$. falciparum and many of these scaffolds are not suitable for the development of drugs for human use [16]. With several millions of compounds already screened, new sources of small molecules are needed for further testing against the malaria parasite [17]. In this context, diversity-oriented synthesis (DOS) offers a possible solution [18-21].

\section{Structural complexity \& diversity-oriented synthesis}

Historically, sources of small molecules for highthroughput screening (HTS) tended to rely on a small number of simple chemical transformations, which has led to very narrow coverage of chemical space for the development of drugs [22] Over the years, advancements in organic synthesis have enabled efficient access to broader chemical space but these advances have only had minimal impact on the nature of small molecules used in HTS. Even today, most screening collections are dominated by flat, $\mathrm{sp}^{2}$-carbon-rich 
heterocycles that are easy to assemble but have minimal chemical complexity. These types of traditional compound collections have underperformed against several biological targets and the need for new types of small molecules for use in HTS are now widely recognized [23].

Chemical complexity in screening collections is important since evidence is mounting for direct correlation of complexity and success in drug-development programs. Although chemical complexity is inherently obvious to practitioners of organic synthesis and medicinal chemistry, it is difficult to define and compute. Lovering and co-workers from Wyeth looked at both $\mathrm{sp}^{3}$-hybridized carbon atoms and chiral centers in a compound as a means to define its complexity [24]. They first retrieved all compounds that entered clinical trials (Phase I, II or III) and the approved drugs from 1980 using GVK BIO database. They calculated the fraction of $\mathrm{sp}^{3}$ content $\left(\mathrm{Fsp}^{3}\right)$, which is the ratio of number of $\mathrm{sp}^{3}$ carbons in a molecule to the total number of carbons. As $\mathrm{Fsp}^{3}$ increases, the compound contains more $3 \mathrm{D}$ character, which can correlate to increased complexity. The analysis shows not only the general increase in the average $\mathrm{sp}^{3}$ content for every stage going from discovery to drugs, but that drugs have a $31 \%$ increase in the $\mathrm{Fsp}^{3}$ content compared with that of compounds in discovery. A similar analysis was carried out on compounds which contain at least one chiral center, another descriptor for complexity. The same enrichment is observed as the average is calculated for each class of compounds ranging from discovery to drugs. In this case, $46 \%$ of the compounds in discovery contain at least one chiral center, while $61 \%$ of drugs contain at least one chiral center, a 33\% increase. Interestingly, the authors go onto correlate increased $\mathrm{sp}^{3}$ content to increased solubility and lower melting points, a descriptor for predicting drug absorption.

In addition, Luker and co-workers from AstraZeneca reported that complexity (as measured by flatness) could be anticorrelated to toxicity [25]. Their analysis focused on a set of internal small-molecule candidates wthat were investigated in rat and dog in vivo toxicology studies over the past 10 years. The authors were attempting to develop a predictive model for preclinical toxicology based off of structural descriptors. Although many properties are described as having a contributing factor in a compound's toxicity, flatness, as measured by the ratio of aromatic atoms to total heavy atoms, was specifically called out as having a statistically relevant impact. Compounds that reached man had an average of $49 \%$ of the atoms being aromatic, while compounds that were stopped due to toxicity had an average aromatic atom

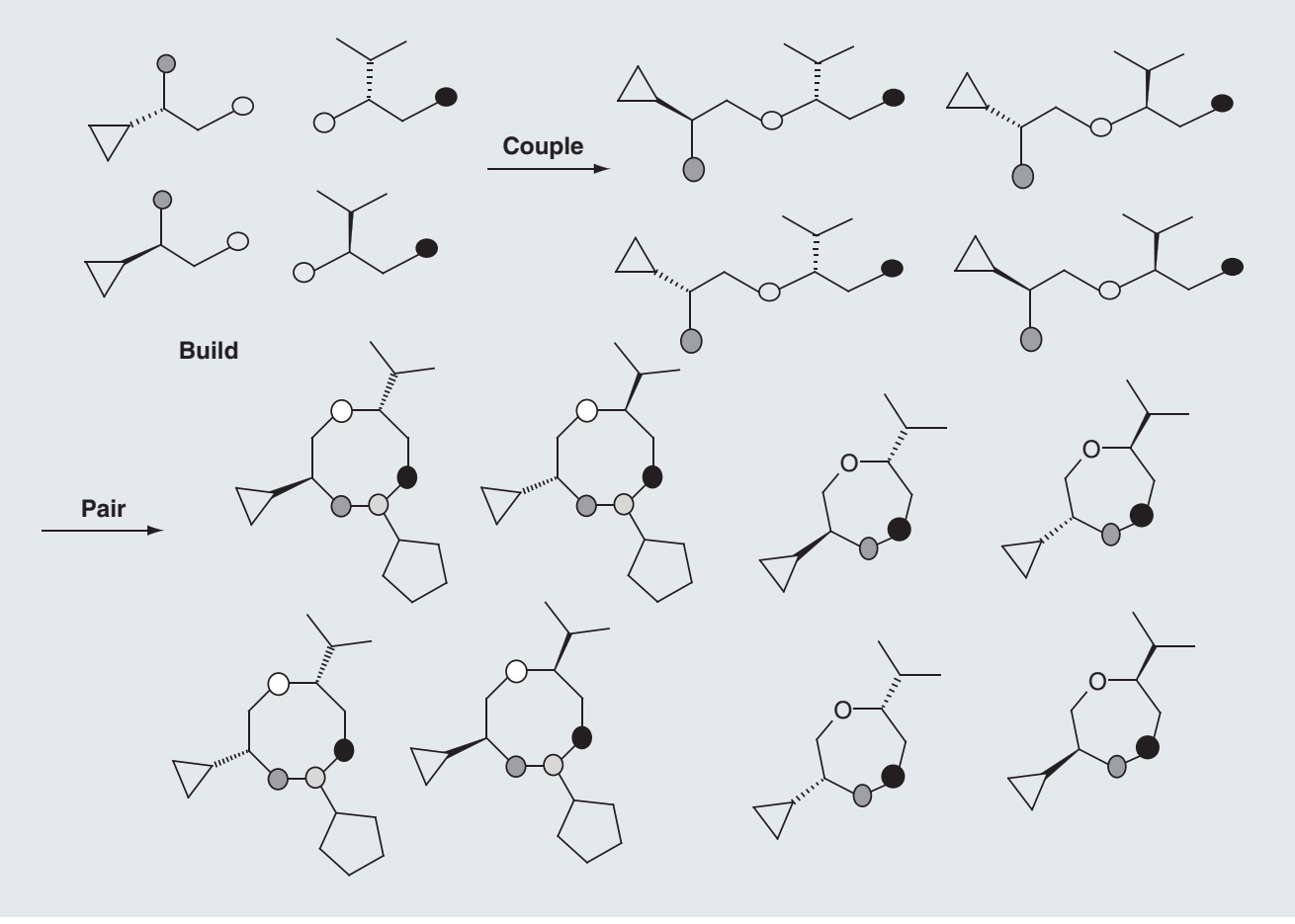

Figure 2. Overview of a build/couple/pair strategy. 
count of $64 \%$. These types of studies suggest that, screening collections need to be populated with compounds with higher chemical complexity and DOS provides a framework for accessing compounds with increased complexity.

DOS is a strategy that allows access to structurally and stereochemically diverse compounds in an efficient manner. Such examples have become prevalent in the literature for the synthesis of complex chemotypes [26-31]. An illustration of these concepts can be shown through a build/couple/pair (B/C/P) approach to DOS (Figure 2) [19,21]. In the build phase, stereochemically enriched linear fragments are accessed, ideally, in all possible stereochemical combinations. In the next phase, the linear chiral fragments are covalently coupled to arrive at complex linear scaffolds. Finally in the pair phase, appropriate intramolecular reactions transform the linear scaffolds into rigidified cyclic skeletons featuring chiral centers in the backbone. Traditional building block level diversity can also be introduced to these complex DOS skeletons through solid- or solution-phase library generation protocols.

The $\mathrm{B} / \mathrm{C} / \mathrm{P}$ algorithm provides a platform for creatively applying modern organic transformations to enable synthesis of complex compounds in a systematic fashion. Ideally $\mathrm{B} / \mathrm{C} / \mathrm{P}$ approach attempts to produce a collection of complex compounds that will have comprehensive stereochemical diversity. In order to achieve that, it is necessary to have a set of complete stereoisomers in the build phase. In addition, the reactions employed in couple and pair phases either do not introduce additional chiral centers or enables the introduction of new stereocenters in all possible combinations. Such rigorous planning during the library synthesis phase can have profound consequences during the subsequent stages of

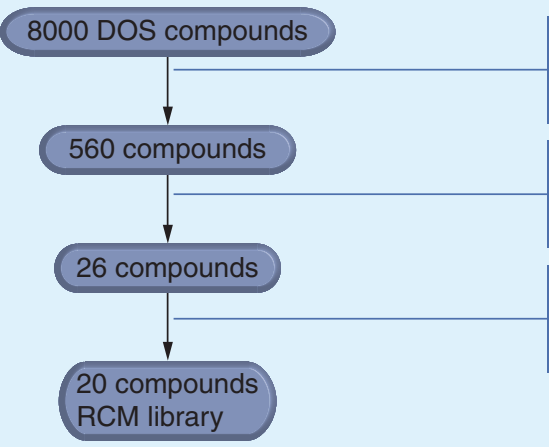

$>90 \%$ inhibition @ $5 \mu \mathrm{M}$ (Dd2, triplicate)

Titration in four point dose (Dd2 and 3d7)

$>50 \%$ at $260 \mathrm{nM}$, equipotent

RCM library selected for validation

Figure 3. Summary of Broad Institute high throughput screening screening campaign.

DOS: Diversity-oriented synthesis; RCM: Ring-closing metathesis. screening, prioritization of compounds for follow-up studies and drug development. Typically, results from HTS from many DOS collections have higher density of information compared with results from traditional collections. For example, if all the stereoisomers of a given compound are already present in the screening collection, stereochemical-structure-activity relationships (SSAR) $[32,33]$ could be readily determined. Furthermore, each chemical scaffold is the result of short modular synthetic pathways executed by the $\mathrm{B} / \mathrm{C} / \mathrm{P}$ approach that enables modification of the atoms that constitute even the core of the chemical scaffold. Hence, DOS is ideally suited for facile and rapid modifications of complex chemical scaffolds for efficient medicinal chemistry in lead optimization programs.

\section{Macrolactams as antimalarials}

Over the past five years, the Chemical Biology Platform at the Broad Institute has created a diverse library of $>100,000$ DOS compounds by applying the $\mathrm{B} / \mathrm{C} / \mathrm{P}$ approach. Compounds in this collection typically contain three or four stereocenters. In addition to stereochemical and scaffold diversity, this collection also features building block level diversity. A full matrix of stereoiosmers combined with building block diversity enables rapid SSAR and structure-activity relationships (SAR) studies. Such novel compound collections are attractive for identifying antimalarial compounds with potentially new modes of action.

A representative collection of this library called an 'informer set' that consisted of 8000 compounds was screened against the multidrugresistant $\mathrm{Dd} 2$ P. falciparum parasite at $5 \mu \mathrm{M}$ in a growth-inhibition assay (FIgUre 3) [34]. A total of 560 compounds showed greater than $90 \%$ inhibition. The list was further triaged to 26 compounds based on dose-response data with four concentrations against both $\operatorname{Dd} 2$ and the wild type $3 \mathrm{~d} 7$ strains. A total of 20 out of 26 compounds came from a single chemical library (ring-closing metathesis [RCM] library) and this scaffold was prioritized for further development. One of these 20 compounds was subjected to full-dose response with 12 concentrations and the $\mathrm{EC}_{50}$ was determined to be $120 \mathrm{nM}$ against the Dd2 strain (Figure 4).

The RCM library is derived from a series of 14-membered macrocycles with four stereogenic centers and was accessed by the $\mathrm{B} / \mathrm{C} / \mathrm{P}$ approach as outlined in Figure 5 [35]. The build phase involved accessing chiral fragments $\mathbf{2}$ through asymmetric aldol reactions and functionalizing 


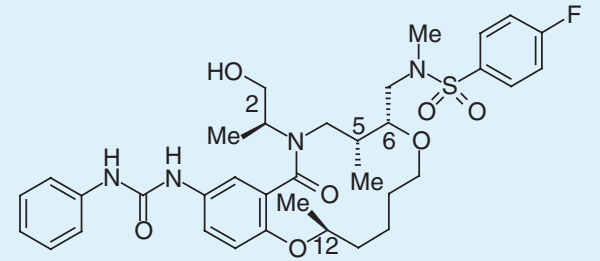

High-throughput screening hit compound

\begin{tabular}{l|c}
\multicolumn{2}{l}{ Stereochemistry $\left(\mathrm{C}_{2} \mathrm{C}_{5} \mathrm{C}_{6} \mathrm{C}_{12}\right):$ SRRS } \\
\hline $\mathrm{Dd} 2\left(\mathrm{EC}_{50}\right)$ & $120 \mathrm{nM}$ \\
$3 \mathrm{~d} 7\left(\mathrm{EC}_{50}\right)$ & $120 \mathrm{nM}$ \\
Hemolysis $\left(\mathrm{EC}_{50}\right)$ & $>40 \mu \mathrm{M}$
\end{tabular}

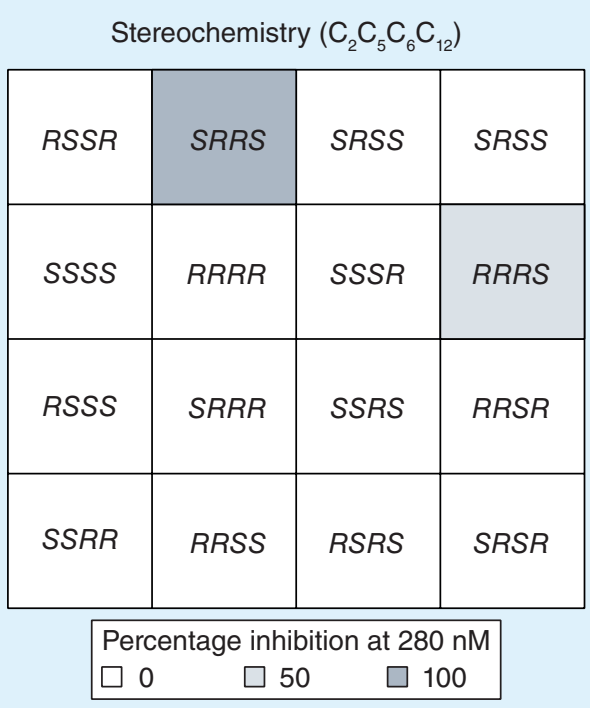

Figure 4. Stereochemical-structure-activity relationships of hit compound.

readily available amino alcohols to afford enantiomeric amines I. In the couple phase, the chiral fragments were connected to make linear amines 3. These were further elaborated to the di-olefin intermediate 4. Finally, the RCM pairing reaction produced the 14-membered macrolactam 5 with four chiral centers.

All sixteen steroiosmers of the macrolactam were accessed by the same synthetic route and building block diversification was later performed on solid phase. Since the library contained all possible stereochemical combinations, the SSAR is readily established and the results are presented in Figure 4. Of the 16 stereoisomers, biological activity is observed in two isomers. These two compounds have the same configuration on all the three internal stereocenters $\left(\mathrm{C}_{5} \mathrm{C}_{6} \mathrm{C}_{12}=R R S\right)$ and opposite configurations on the exocyclic stereocenter $\left(\mathrm{C}_{2}=S\right.$ or $\left.R\right)$.

The most potent compound SRRS, HTS hit compound, was not toxic to erythrocytes but was insoluble in aqueous solution $(<0.5 \mu \mathrm{M}$ in water), which hindered analysis in further assays. SAR studies were initiated on this compound focusing on substituents at three areas of the molecule: aniline site; amine side chain; and lactam side chain, with a goal of improving potency and aqueous solubility.<smiles>CCCCCC(C)N</smiles>
Two stereoisomers<smiles>CN(C)CC(C(=O)OC(C)(C)C)=C(C(=O)O)C(=O)O</smiles>

2

Four stereoisomers

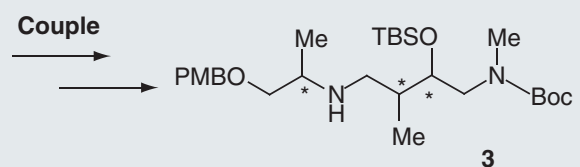

Eight stereoisomers

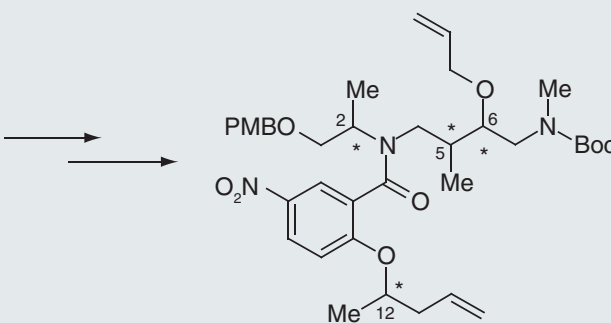

16 stereoisomers

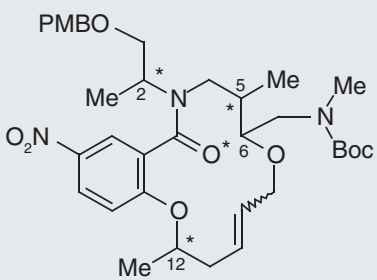

5

16 stereoisomers

Figure 5. Preparation of macrocycles using the build/couple/pair strategy. 
Representative results from the SAR studies are shown in Figure 6. Results from a small set of analogs showing variations at the aniline site is shown in the left panel of Figure 6. While all analogues saw a loss of potency, 4-amino3,5-dimethylisoxazoyl urea analogue 10 provided enhanced aqueous solubility with submicromolar potency. The SAR around the amine side chain (middle panel; Figure 6) was steep with no improvement on the initial $p$-fluorosulfonamide analogue. Other sulfonamides at this position showed decreased potency while replacing the sulfonamide with a number of other functional groups including alkyl groups or carbamates resulted in loss of activity. Thus, the $p$-fluorosulfonamide portion of $\mathbf{6}$ represents an essential pharmacophore.
Finally, substituents of the amide side chain were investigated (right panel; Figure 6). Interestingly the p-methoxybenzyl ether 17, which is accessed on route to alcohol $\mathbf{6}$, had subnanomolar potency $(\mathrm{L} / \mathrm{D}=0.18 \mathrm{nM})$. A range of groups were appended to the alcohol and showed similar improvements, but lacked solubility in water. The solution to the compound's poor solubility came from the introduction of nitrogen-based functional groups. As shown in Figure 6, introduction of an azide produced a highly potent analogue (18) but one still lacking aqueous solubility. Staudinger reduction followed by bis-methylation of the resultant amine afforded a compound with both subnanomolar potency $(\mathrm{L} / \mathrm{D}=0.54 \mathrm{nM})$ and solubility in water (water solubility $=124 \mu \mathrm{M}$ ), achieving the initial

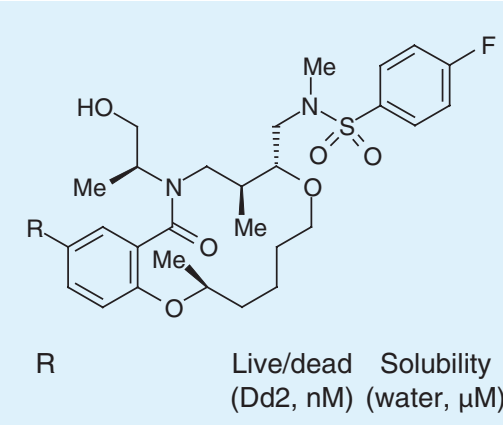

120

$<0.5$<smiles>NCC1CC1</smiles>

988

7

577

$<0.5$<smiles>CNc1nc2ccccc2o1</smiles>

$577<0.5$<smiles>CNC(=O)NC(C)C</smiles><smiles>CCNC(=O)Nc1c(C)noc1C</smiles>

10<smiles>CCNS(=O)(=O)c1ccccc1</smiles>

11<smiles>ClCNc1ccccc1</smiles>

$\mathrm{R}$<smiles>[M]C(CN(CC(C)C)C(=O)c1ccccc1OC(C)C)C(CN([R])C)OCCCCCO</smiles>

Live/dead Solubility (Dd2, nM) (water, $\mu \mathrm{M}$ )<smiles>[R]CC(C)N(CC([M])[C@H](CN(C(C)C)S(=O)(=O)c1ccc(F)cc1)OCCCC[C@H](C)O[Na])C(=O)c1cc(NC(=O)Nc2ccccc2)ccc1OC(C)(C)C</smiles>

$\mathrm{HO} \mathrm{S}^{3}$

6

120

$<0.5$

$\mathrm{MeO}$<smiles>CCS(=O)(=O)c1ccccc1F</smiles>

1100

$<0.5$

12<smiles>O=S(=O)(I)c1ccc(C(F)(F)F)cc1</smiles>

877

$<0.5$

13<smiles>CCc1ccc(F)cc1</smiles>

4270

$<0.5$

$\mathrm{H}_{2} \mathrm{~N}_{3}$

270

370

14<smiles>CC(=O)Oc1ccccc1</smiles>

$>5000$

1.2

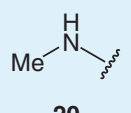

400

79

20

$\mathrm{Me}_{21}^{-\mathrm{Ne}}$
0.54

120

79

Figure 6. Comparison of antimalarial activity. Structure-activity relationships of the aniline, amine and lactam substituents. 
objective of discovering a highly potent antimalarial with good aqueous solubility. This compound is more potent than chloroquine or artesunate, and is similar in potency to atovaquone. Compound $\mathbf{2} \mathbf{I}$ is a promising antimalarial with a unique chemotype and subnanomolar activity in multiple malaria strains. It is soluble in water and nontoxic to erythrocytes and HepG2 cells. Studies to discover the mechanism of action for this new class of antimalarial agents are currently in progress.

\section{Spiroindole antimalarials from Novartis}

In 2010 the Novartis Institute for Tropical Diseases, the Genomics Institute of the Novartis Research Foundation, the Biomedical Primate Research Centre and the Swiss Tropical Institute reported a screening campaign of 12,000 compounds that uncovered antimalarial agents with a potentially new mechanism of action $[36,37]$. The key strength of their strategy was their compound collection, which contained 10,000 synthetically diverse compounds together with 2000 natural products. All these novel compounds were exposed to a phenotypic growth inhibition assay against the blood-stage parasite of malaria. HTS against $P$. falciparum growth inhibition with all the 12,000 compounds led to the identification of 275 compounds with submicromolar activity (Figure 7). Further toxicity analysis and upon considering physical and pharmacokinetic properties, spiroazepineindole $\mathbf{2 5}$ was singled out for further development.

This lead compound was prepared using the build/couple/pair strategy for developing complex and diverse libraries. Thus, synthesis of spiroazepineindole 25 involved an initial build phase (FIGURE 8) in which 22 was prepared. This fragment contained functionality that could, at first, partake in a condensation reaction with 5-bromoisatin (23). Sequential in situ diastereoselective pairing using the Pictet-Spengler cyclization afforded the spiroazepineindole 25. Chiral resolution of the reaction products demonstrated the importance of having access to every possible stereoisomer in a diversity library. Testing the enantiomers of $\mathbf{2 5}$ in vitro against the NF54 parasite strain showed that the $(R, S)-\mathbf{2 5}$ was 250 -fold more potent than its $1 S, 3 R$ stereoisomer (TABle I).

By simply switching the starting indoleamine to an analogue with one less methylene unit Novartis chemists could readily change the size

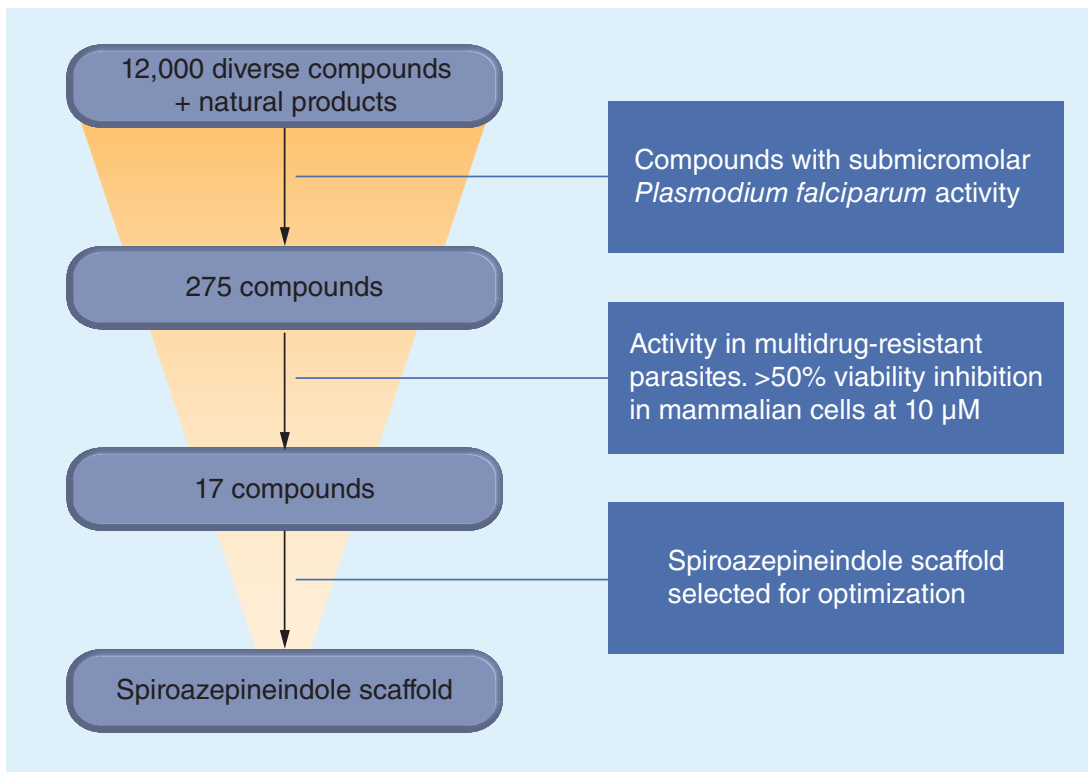

Figure 7. Summary of Novartis high-throughput screening campaign.

of the primary hit (7-membered spiroazepineindole 25) to 6-membered spirotetrahydro $\beta$-carboline 30 (termed spiroindolone) (Figure 9). Thus amine $\mathbf{2 8}$ could be obtained starting from D-tryptophanol, through overall reduction of the hydroxymethyl group in $\mathbf{2 6}$ to a methyl group. A diastereoselective Pictet-Spengler reaction provided the trans isomer $(1 R, 3 S)-\mathbf{3 0}$ as the major component. This synthetic sequence nicely demonstrates the modular nature of $\mathrm{B} / \mathrm{C} / \mathrm{P}$ approach that is needed for rapid analog synthesis during the medicinal chemistry optimization phase. The use of L-tryptophanol allowed for the preparation of the enantiomer of $\mathbf{3 0}$ and as reaction products provided the separable cis isomer, a full complement of stereoisomers could be obtained. In practice, Novartis chemists preferred a

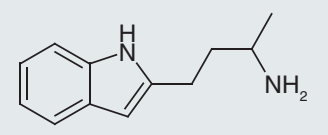

22

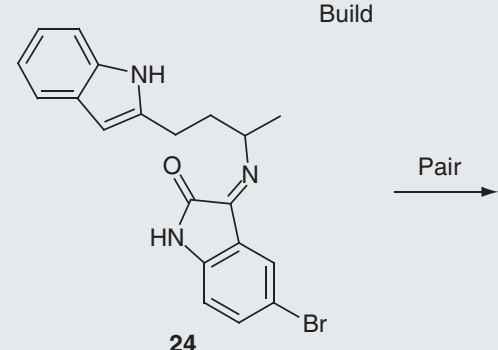

24<smiles>O=C1Nc2ccc(Br)cc2C1=O</smiles>

23
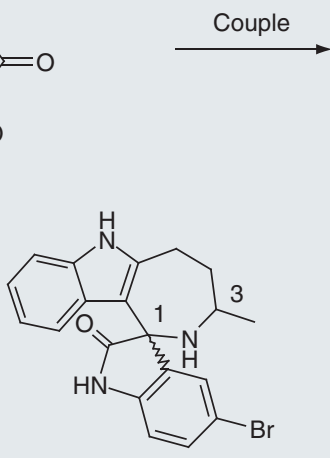

25
Figure 8. Preparation of spiroazepineindole 25 using a build/couple/pair strategy. 
Table 1. Pharmacokinetic profile and in vitro antimalarial activity of spiroindolones.

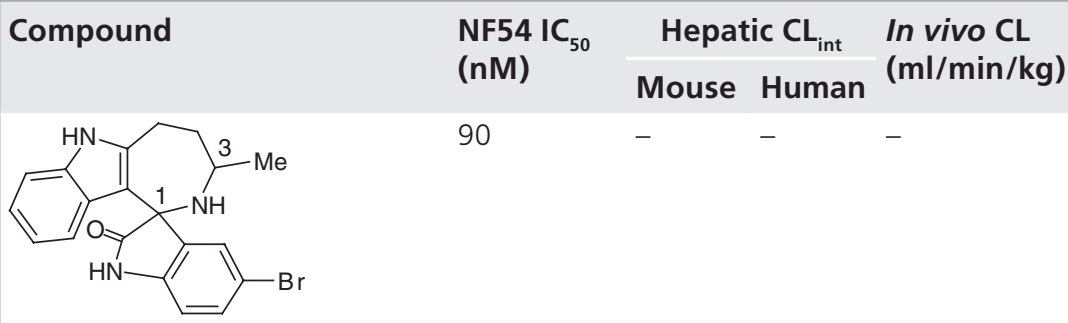

Racemic 25

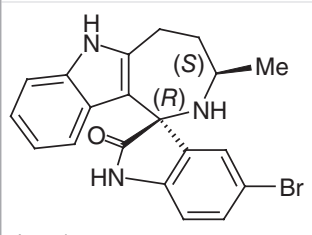

$(R / S)-25$

$(S / R)-25$

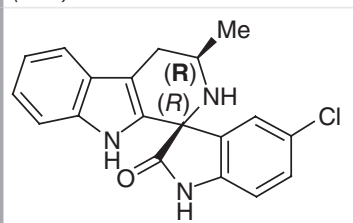

$(R / R)-30$

$(S / S)-30$

$(R / S)-30$

$(S / R)-30$

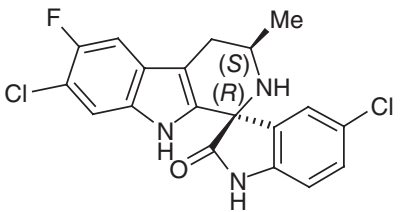

$(R / S)-31$

$(S / R)-21$
20

$\begin{array}{llll}>5000 & - & - & - \\ 444 & - & - & -\end{array}$

$\begin{array}{llll}- & 1808 & - & - \\ 9 & \text { High } & \text { High } & 49.66 \\ >5000 & \text { Low } & \text { Low } & - \\ 0.9 & \text { Low } & \text { Low } & 9.75\end{array}$

molecule without having to develop new chemistry. Compound $(R, S)$-3I, known as NITD609, has potency in the low nanomolar range and shows no cross-resistance against a number of drug resistant strains, suggesting a new mechanism of action. While certain established compounds such as chloroquine are specifically active against late-stage (trophozoite) parasite activity, NITD609 showed potency at early and late $P$. falciparum development, although both did not inhibit parasite growth as quickly as the artemisinin derivatives. Although it would also be advantageous to have a compound active in both erythrocytic and exo-erythrocytic parasite stages, a study which included NITD609 revealed that it was inactive in the Plasmodium liver stages [38].

NITD609 showed low binding to hERG and to a series of human G-protein-coupled receptors, enzymes, and ion channels. No significant cytotoxicity was observed against a panel of in vitro mamalian cell lines and it was not mutagenic. In oral and intravenous PK studies in mice and rats, NITD609 had properties compatible with a once-daily oral dosing regimen. This compound had a good half-life $\left(t_{1 / 2}=10\right.$ and $27.7 \mathrm{~h}$, respectively), moderate volume of distribution $\left(\mathrm{V}_{S S}=2.11\right.$ and $\left.3.04 \mathrm{l} / \mathrm{kg}\right)$, a low total systemic clearance $(\mathrm{Cl}=9.75$ and $3.48 \mathrm{ml} \mathrm{min}^{-1} \mathrm{~kg}^{-1}$ mouse and rat, respectively) and excellent bioavailability $(\mathrm{F}=100 \%)$. Current antimalarial treatments require drugs to be taken between one and four times a day for up to 7 days. This is a significantly disadvantage in resource deficient regions were medical supervision is limited, thus the possibility of developing a once daily oral drug could make treatment significantly easier. In a P. berghei malaria mouse model, infection was completely cleared at a single oral dose of $100 \mathrm{mg} / \mathrm{kg}$ while three daily oral doses of $50 \mathrm{mg} / \mathrm{kg}$ also afforded a complete cure.

The ultimate goal of this study was to uncover new mechanisms of action for an antimalarial compound. In order to identify the target of NITD609, an excellent strategy is to apply resistance selection coupled with the next generation sequencing. In this approach sublethal drug pressure is applied to a parasite strain until resistance to the drug is developed. Analysis of the genome of the drug-resistant strain can reveal the basis for resistance and the target of the compound. When a similar strategy was applied by Novartis researchers using NITD609 and the Dd2 parasite strain it was discovered that a high number of passages was necessary to achieve modest 
resistance. Specifically it required 3-4 months of constant drug pressure to observe a 7 - to 24 -fold decrease in $\mathrm{IC}_{50}$ values. This suggests that the parasites have difficulty developing resistance and could be an important and positive attribute of this compound. Significantly, none of the resistant parasites showed cross-resistance to a panel of known antimalarial agents suggesting a new mechanism of action. Analysis of the resistant line genome relative to the nonresistant parental reference line identified mutations in pfatp 4 , which is a cation transporting P-type adenosine triphosphatase. While further work is necessary to establish whether PfATP4 is the true target of NITD609 or part of a mechanism to reduce its effectiveness, its identification suggests a departure from the know mechanisms of action of the existing antimalarials. NITD609 is currently in Phase IIa clinical trials and would represent the first antimalarial with a novel mechanism of action to progress to this stage in the last 20 years.

\section{Antimalarial compounds from chemical methodology development}

Another example of novel antimalarials being discovered through the screening of structurally diverse and complex scaffolds was shown through collaborative work carried out at the Center for Chemical Methodology and Library Development at Boston University (CMLD$\mathrm{BU})$ and the NIH Chemical Genomics Center (NCGC) [38]. CMLD-BU's focus is on the development of modern organic chemistry methods for the use in library synthesis of small molecules for HTS. Similar to structures in previous sections, the CMLD-BU collection of compounds incorporates structural diversity as measured by $\mathrm{sp}^{3}$ content and the number of stereogenic centers. Another analysis emphasizing the structural diversity of the CMLD-BU collection was achieved by looking at chemical shape space through the plotting of principle moments of inertia. As described by Sauer and Schwarz, principle moments of inertia plots using standard reference points (acytelene, benzene and adamentane as rod, disc and sphere shapes, respectively) allow for a $2 \mathrm{D}$ representation of $3 \mathrm{D}$ shape [39]. Figure 10 shows the spherical shape space heavily represented compared with that of flat or rod-like shape. This is in stark contrast to the typically flat compounds largely found in commercially available libraries.

The NCGC is a Comprehensive Screening Center in the Molecular Libraries Probe Production Centers Network. As part of the National Center for Advancing Translational Sciences division of preclinical innovation, the NCGC aims to translate discoveries from the human genome project into biological and disease insights through, in part, small-molecule assay development and HTS. In the case of identifying novel antimalarials, the NCGC used a SYBR green I dye DNA staining assay to measure proliferation of $P$. falciparum in human erythrocytes. The compounds were profiled against five geographically distinct parasites (CP250, Dd2, HB3, 7G8 and GB4) for possible insight into a target depending on the range of activity. The primary HTS was run in dose, a unique approach

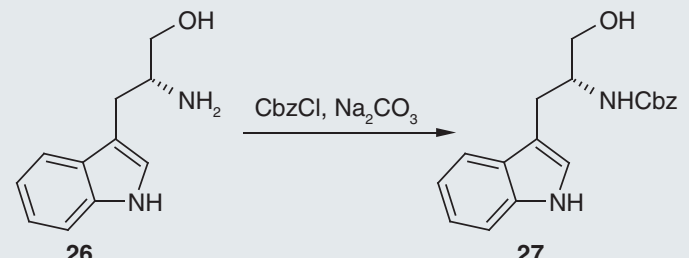

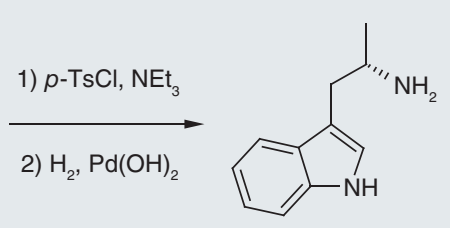

28

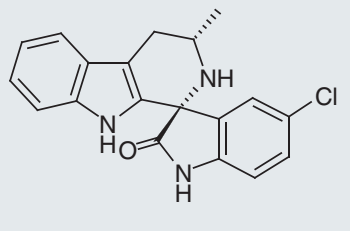

$R S-30$

Figure 9. Preparation of spirotetrahydro $\beta$-carboline 30. 


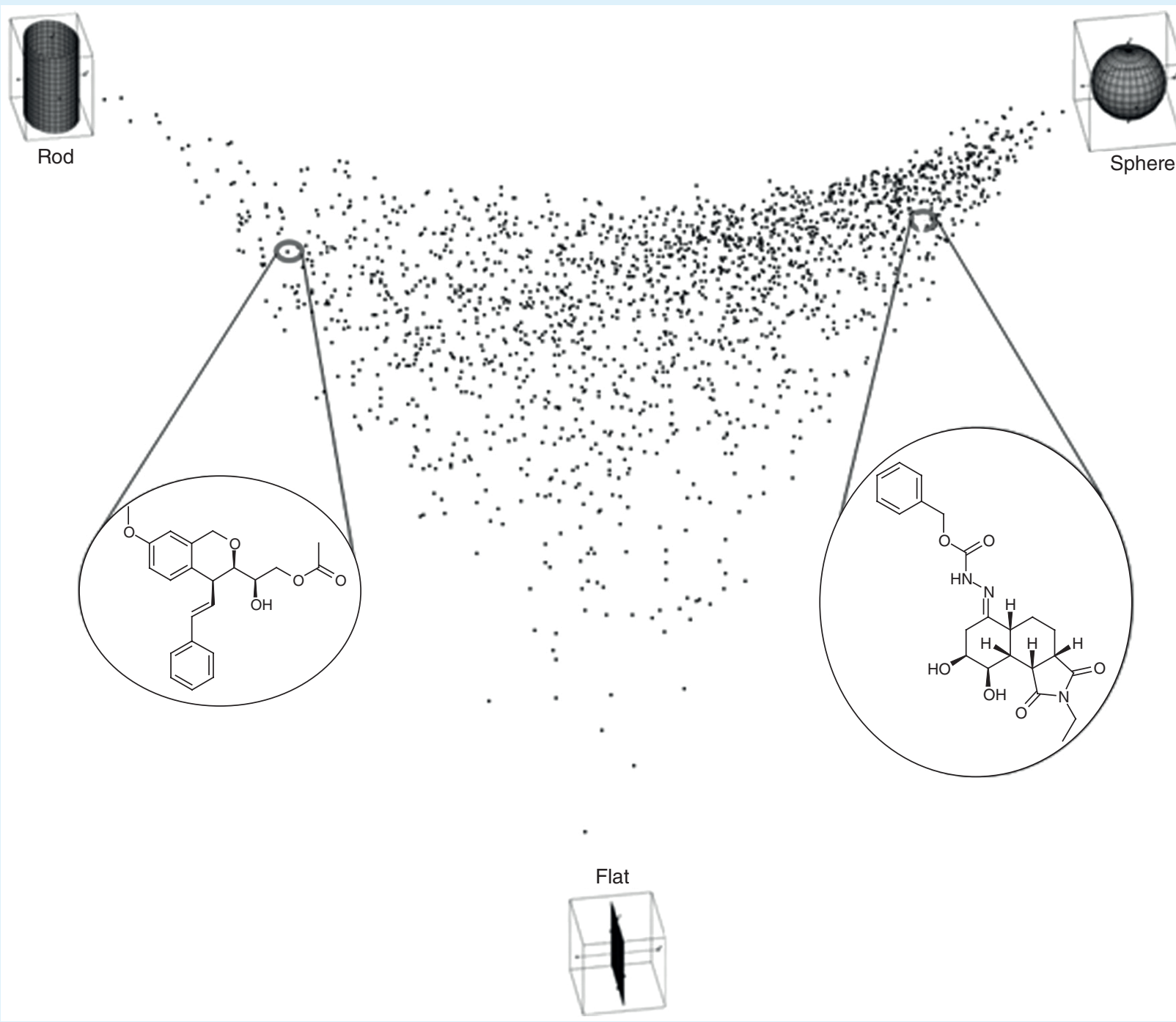

Figure 10. Positive material identification analysis of the Center for Chemical Methodology and Library Development at Boston University small-molecule collection.

Reproduced with permission from [39].

by NCGC named quantitative high-throughput screening (qHTS), in an attempt to reduce the number of false positives often identified in a single-concentration HTS. Combining these screening capabilities offered by NCGC with CMLD-BU's unique small-molecule collection covering underrepresented chemical space created an opportunity for the discovery of novel antimalarials. This section will describe three novel scaffolds identified in the aforementioned HTS campaign.

The first example of novel scaffolds having antimalarial activity in the CMLD-BU collection focused on a conserved indoline alkaloid scaffold. These compounds were generated through an inverse-demand Diel-Alder reaction developed in the Snyder laboratory at Boston University. Coupling substituted tryptophan $\mathbf{3 2}$ with triazine $\mathbf{3 3}$ gave Diels-Alder precursor $\mathbf{3 4}$ (Figure II). Acylation with trifluoroacetic anhydride followed by heat gave the Diels-Alder adduct. Purification by silica gel revealed the secondary amine, which was then subsequently capped with either sulfonyl or acyl chlorides. Besides the appendage diversity for the generation of SAR in HTS, a complementary approach with indolylpropionic acids created additional skeletal diversity within the scaffolds. The 
<smiles>[2H]c1ccc2[nH]cc(CC(N)C(C)=O)c2c1</smiles>

32<smiles>COC(=O)c1nnc(C)nc1OC</smiles>

33

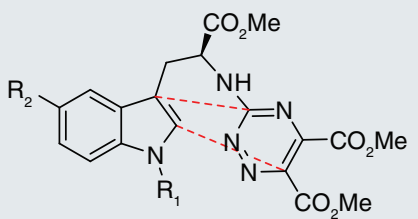

34

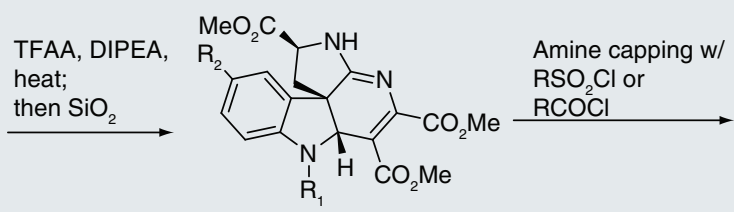

35

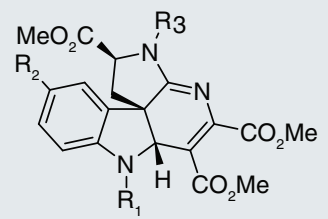

36

Figure 11. Synthesis of an indoline alkaloid-based library.

CMLD-BU collection contained 199 indoline alkaloids, which were screened for antimalarial activity.

The indoline alkaloid scaffold $\mathbf{3 6}$ proved to be an ideal motif for malaria-growth inhibition. Both 36a and 36b were found during the qHTS to have pan activity against the five malaria strains with $\mathrm{IC}_{50}$ values of single-digit micromolar (TABLE 2). Neither compound showed any toxicity in HEK293 or HepG2 cells. SAR showed the necessity of an aryl sulfonamide at the pyrrolidine nitrogen and the benzyl substituent at the indole nitrogen. The lack of hits from other similar skeletons derived from the indolylpropionic acid suggests the importance of the structural complexity for activity. Initial medicinal chemistry efforts have generated several analogs with nanomolar $\mathrm{IC}_{50}$ values through ortho substitution on the benzyl group and optimization of the sulfonamide (36c \& 36d; TABLE 2).

The asymmetric Mannich reaction has allowed access to stereochemically diverse motifs for the synthesis of complex scaffolds. Schaus et al. demonstrated this through the synthesis of enantioenriched dihydropyrimidinones and guanidines using $\beta$-amino esters generated stereoselectively with the Mannich reaction [40,41].

Table 2. Indoline alkaloids identified with antimalarial activity through highthroughput screening (36a and $36 \mathrm{~b}$ ) and examples from subsequent medicinal chemistry efforts (36c and 36d).

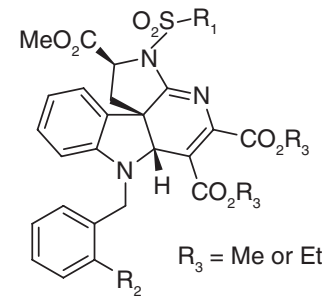

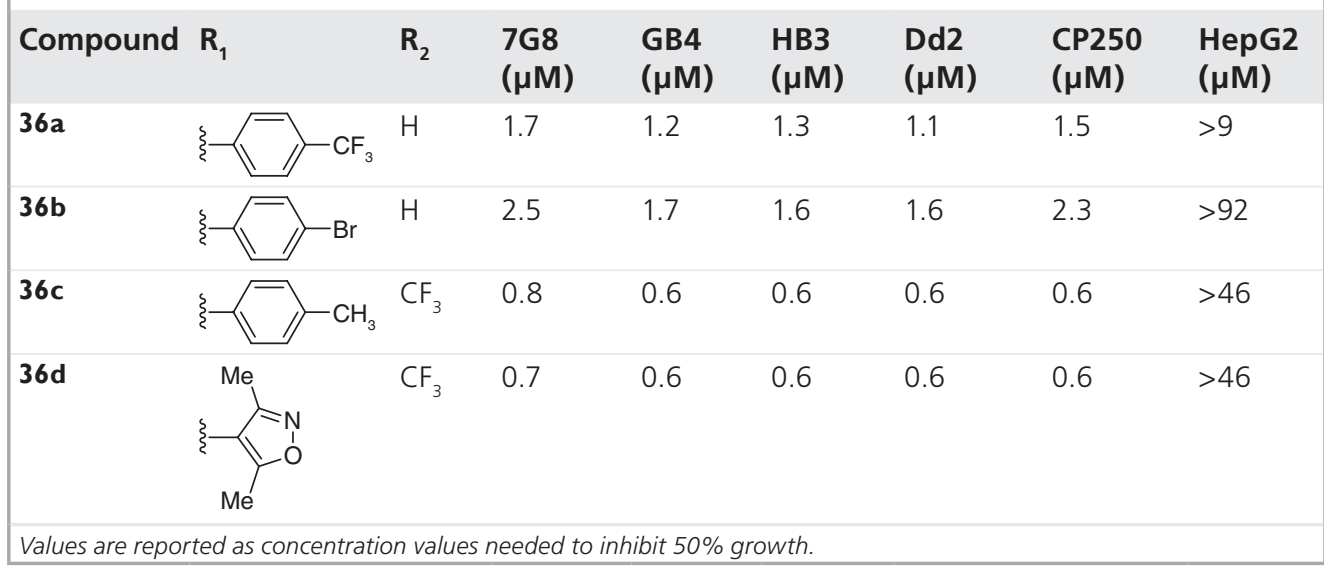




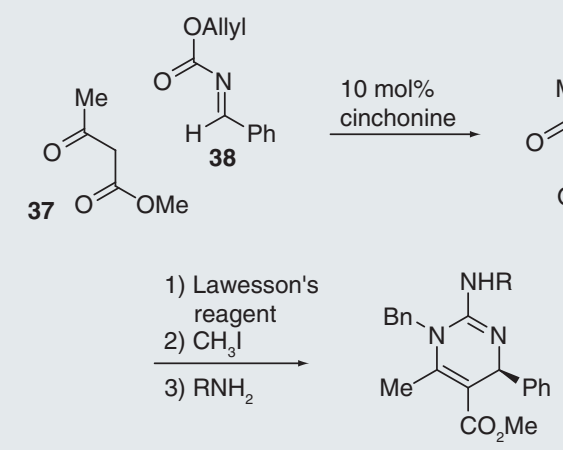

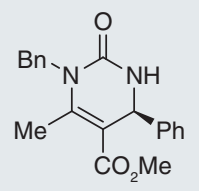

$40 \mathrm{a}$

39

2) $\mathrm{AcOH}, \mathrm{EtOH}, \mu$ wave

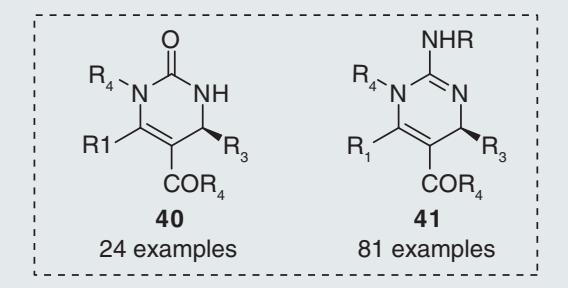

Figure 12. Synthesis of dihydropyrimidinones and guanidines

Highly stereoenriched $\beta$-amino ester 39 is generated from reaction with ketoester 37 and imine 38 in the presence of catalytic cinchonine (Figure 12). Both stereoisomers are possible by catalyst control, allowing for evaluation of SSAR in biological screens. Allyl deprotection in the presence of benzyl isocyanate followed by condensation generates the dihydropyrimidinone 40a. Further elucidation to the guanidine was achieved by a three-step sequence using Lawesson's reagent, followed by methyl iodide and reaction with an amine. This pathway was utilized for the synthesis of 24 dihydropyrimidinones (structurally represented by $\mathbf{4 0}$ in Figure 12) and 81 guanidines (structurally represented by $\mathbf{4 I}$ ), which were included in the CMLD-BU collection screened at NCGC for malaria growth inhibition.

Interestingly, screening results showed compounds containing the guanidine motif as the only examples from the CMLD-BU collection to have strain-selective activity. The qHTS identified only six compounds containing $>$ fivefold differential activity between any two lines, two of which were closely related by structure (4Ia \& 4lb; TABLE 3). These two compounds show preferential activity towards GB4, with approximately fourfold selectivity over $\operatorname{Dd} 2$ and 40 to 100 -fold selectivity over CP250, 7G8 and HB3. Since these compounds were original screened in racemic fashion, chemistry efforts begin with the synthesis of optically pure $\mathbf{4} \mathbf{l} \mathbf{b}$. A stereochemical dependence on activity was observed with the $R$ isomer of $\mathbf{4} \mathbf{l b}$ being tenfold more active against GB4. A similar trend is seen in the activity against $\mathrm{Dd} 2$. Interestingly, no difference in activity is observed for $7 \mathrm{G} 8$ and HB3 strains. Optimization efforts provided 4Ic, which has an $\mathrm{IC}_{50}$ of $20 \mathrm{nM}$ against $\mathrm{GB} 4$ strain growth and 275-fold selectivity over 7G8, while

Table 3. Guanidines identified with strain-selective antimalarial activity through HTS (4la and $4 \mathbf{l} \mathbf{b}$ ) and examples from subsequent medicinal chemistry efforts (4lc-4lf).

\begin{tabular}{|c|c|c|c|c|c|c|c|c|c|}
\hline Compound & $R_{1}$ & $\mathbf{R}_{2}$ & $\mathbf{R}_{3}$ & $7 \mathrm{G} 8(\mu \mathrm{M})$ & GB4 ( $\mu \mathrm{M})$ & HB3 $(\mu M)$ & $\mathrm{Dd} 2(\mu \mathrm{M})$ & $\mathrm{CP} 250(\mu \mathrm{M})$ & HepG2 $(\mu \mathrm{M})$ \\
\hline $41 a$ & Et & $\mathrm{CF}_{3}$ & $\mathrm{CF}_{3}$ & 5.0 & 0.05 & 6.1 & 0.2 & 2.1 & $>9$ \\
\hline $4 \mathrm{Ib}$ & Et & $\mathrm{Cl}$ & $\mathrm{CF}_{3}$ & 7.5 & 0.4 & 6.8 & 1.8 & 5.1 & $>9$ \\
\hline$R-4 \mid \mathbf{b}$ & Et & $\mathrm{Cl}$ & $\mathrm{CF}_{3}$ & 9.5 & 0.2 & 14 & 0.8 & - & - \\
\hline S-4Ib & Et & $\mathrm{Cl}$ & $\mathrm{CF}_{3}$ & 9.8 & 2.8 & 11 & 6.0 & - & - \\
\hline $4 / c$ & $p-\mathrm{CF}_{3} \mathrm{Bn}$ & $\mathrm{CF}_{3}$ & $\mathrm{Cl}$ & 5.5 & 0.02 & 7.3 & 0.4 & 1.5 & 22 \\
\hline $4 / d$ & $p-\mathrm{CF}_{3} \mathrm{Bn}$ & $\mathrm{CF}_{3}$ & $\mathrm{H}$ & 5.3 & 0.04 & 6.8 & 0.9 & 2.8 & 7.9 \\
\hline $41 \mathrm{e}$ & $m-\mathrm{CF}_{3} \mathrm{Bn}$ & $\mathrm{CF}_{3}$ & $\mathrm{Cl}$ & 3.0 & 0.04 & 2.7 & 0.1 & 0.2 & 1.1 \\
\hline
\end{tabular}


(A)<smiles>CCC#Cc1cc(OC)c(OC)cc1C=O</smiles>

42

(B)<smiles>O=Cc1cc(Br)c(P)c(Br)c1Br</smiles>

45

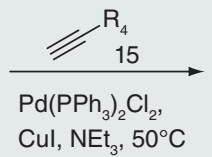

$\mathrm{Cul}, \mathrm{NEt}_{3}, 50^{\circ} \mathrm{C}$

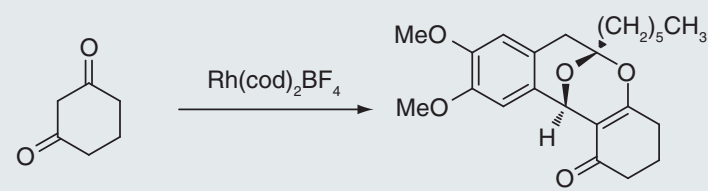

43

44

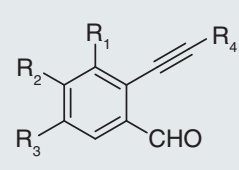

46

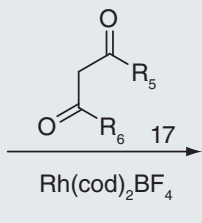

$\mathrm{Rh}(\operatorname{cod})_{2} \mathrm{BF}_{4}$

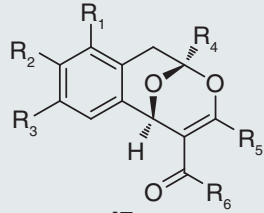

47

Figure 13. Diversity-oriented synthesis of polycyclic ketals. (A) Discovery of a rhodiumcatalyzed cycloisomerization and nucleophilic addition to give a tetracyclic ketal; (B) application of the pathway for library synthesis of polycyclic ketals.

remaining largely nontoxic. Appendage modification at $\mathrm{R}_{1}$ and $\mathrm{R}_{3}$ did not have a large effect on GB4 activity, but did increase antimalarial activity against other strains, as well as toxicity in HepG2 cells.

Beeler and co-workers discovered a novel route to polycyclic ketals through multidimensional reaction screening. Reaction of alkynyl aldehyde $\mathbf{4 2}$ with 1,3-cyclohexyldione (43) in the presence of catalytic rhodium gave unexpected tetracyclic ketal 44 in good yield (Figure I3A) [42]. Taking advantage of the novel pathway, a small library of compounds was synthesized following the reaction scheme depicted in Figure I3B [38]. Synthesis started with the Sonogashira coupling of ortho-bromo benzaldehydes with an alkyne to give $\mathbf{4 6}$. Reaction of $\mathbf{4 6}$ with a number of diones and catalytic rhodium gave the now expected polycyclic ketals 47 . ninety compounds were synthesized and met the requirements for purity and quantity to be included in the CMLD-BU small molecule collection.

The most potent antimalarial polycyclic ketals from the CMLD-BU collection are shown in Figure 14 (47a \& 47b). Medicinal chemistry efforts afforded 47c with slightly improved potency against the different strains. Although SAR was limited, aliphatic chains at the bridge head, as seen in $\mathbf{4 7 a}$ and $\mathbf{4 7 c}$, are prevalent in all of the structures with the exception of $\mathbf{4 7 b}$. Substitution on the aryl ring of the benzyaldehyde also seemed to be required for activity. The compounds showed no toxicity against HepG2, HEK293 or red blood cells.

\section{Conclusion}

Studies of amber preserved mosquitoes that are approximately 30 million years old are the

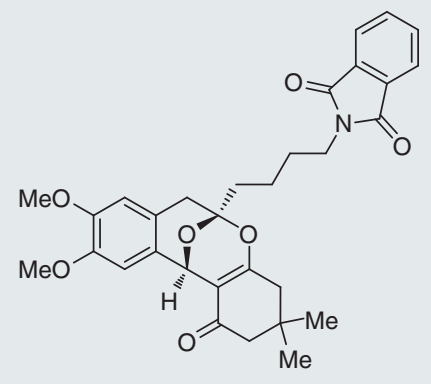

$47 a$

$\mathrm{IC}_{50}=2.5-8.7 \mu \mathrm{M}$ for

7G8, GB4, HB3, Dd2, CP250

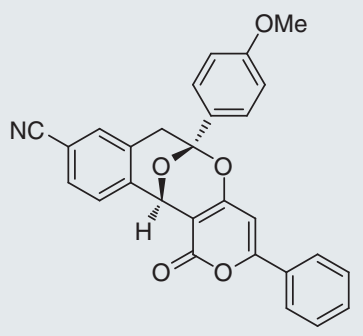

47b $\mathrm{IC}_{50}=1.3-9.0 \mu \mathrm{M}$ for $7 \mathrm{G} 8, \mathrm{~GB} 4, \mathrm{HB} 3, \mathrm{Dd} 2$

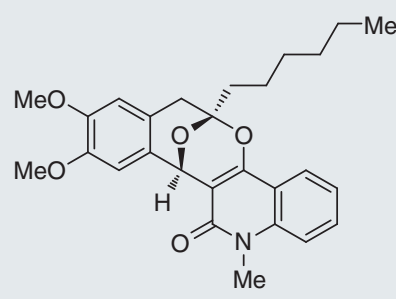

$47 \mathrm{c}$

$\mathrm{IC}_{50}=1.0-6.0 \mu \mathrm{M}$ for 7G8, GB4, HB3, Dd2, CP250

Figure 14. The most potent polycyclic ketals identified from the Center for Chemical Methodology and Library Development at Boston University collection. 
earliest record of the existence of the malaria parasite, and hence the impact and treatment of this parasitic disease has been closely linked to the evolution and survival of humankind [43]. From early herbal treatments such as garlic, powders from Peruvian bark (cinchona or quinine) and the Qinghao plant (artemisia annua L), to the introduction of more modern drug therapies (second generation quinine drugs), societies have worked diligently to identify effective treatments for malaria. Successes have been short lived with no cure to date. This is not due to a lack of research effort, but because resistance of the parasite to drug treatment has been problematic. The ultimate goal of malaria research should be to cure the disease; however, until this happens the need for new effective and safe drugs that are less susceptible to resistance is paramount for the treatment of malaria. The challenge as noted in the introduction is identifying where the new drugs will come from. Global screening efforts to the best of our knowledge have exhausted the traditionally available chemical space. And as such, new sources of small molecules are needed, which will lend themselves to unique biological targets. Whether these new target will be less susceptible to rapid resistance will need to be tested, but at the very least we will have time to further our understanding of the biology of this parasite with the hopes of finally identifying a cure for this life threatening disease. To this end, DOS offers such a solution. In a short period of time the DOS approach has provided novel chemical hits that have advanced into clinical studies as elegantly exemplified by the work of Novartis. These results taken together are very encouraging and efforts to develop such chemistries should be highly encouraged.

\section{Financial \& competing interests disclosure}

The authors wish to thank the NIH for support for some of the work mentioned in this manuscript. The authors have no other relevant afflictions or financial involvement with any organization or entity with financial in or financial conflict with the subject matter or material discussed in the manuscript apart from those disclosed.

No writing assistance was utilized in the production of this manuscript.

\section{Executive summary}

\section{Background}

- Chemotherapy is the most effective tool for controlling malaria.

- Drug resistance is hindering the control of malaria.

\section{Drug discovery against malaria}

- With several million compounds already screened, new sources of small molecules are needed for further testing against the malaria parasite.

- Diversity-oriented synthesis (DOS) offers a possible solution.

\section{Structural complexity \& DOS}

- Chemical complexity in screening collections is important since evidence is mounting for direct correlation of complexity and success in drug development programs.

- Complexity can be defined by the fraction of $\mathrm{sp}^{3}$ content $\left(\mathrm{Fsp}^{3}\right)$ that is the ratio of the number of $\mathrm{sp}^{3}$ carbons in a molecule to the total number of carbons.

- The build/couple/pair (B/C/P) approach to DOS affords compounds with high Fsp ${ }^{3}$ content.

\section{Macrolactams as antimalarials (Broad institute)}

- 14-membered macrolactam with four chiral centers was identified.

- Of the 16 stereoisomers, biological activity was observed in just two isomers. These two compounds have the same configuration on all the three internal stereocenter. Potency for the series ranged from 600 to $0.18 \mathrm{nM}$.

\section{Spiroindole antimalarials from Novartis}

- NITD609 is curative in Plasmodium berghi malaria mouse model at a single $100 \mathrm{mg} / \mathrm{kg}$ dose.

- Resistance selection strategy identified mutations in pfatp, which is a cation-transporting P-type adenosine triphosphatase.

- NITD609 is in Phase lla clinical trials.

\section{Antimalarial compounds from chemical methodology development}

- Efforts from the Center for Chemical Methodology and Library Development at Boston and the NIH Chemical Genomics Center.

- Three novel scaffolds identified as novel antimalarials: indoline alkaloid-based, guanidine and polycyclic ketal scaffolds.

\section{Conclusion}

- DOS approach has provided novel chemical hits that have advanced into clinical studies as exemplified by NITD609. 


\section{References}

1 Ekland EH, Fidock DA. In vitro evaluations of antimalarial drugs and their relevance to clinical outcomes. Int. J. Parasitol. 38(7), 743-747 (2008)

2 Greenwood BM, Fidock DA, Kyle DE et al. Malaria: progress, perils, and prospects for eradication. J. Clin. Invest. 118(4), 1266-1276 (2008).

3 Thera MA, Doumbo OK, Coulibaly D et al. A field trial to assess a blood-stage malaria vaccine. N. Engl. J. Med. 365(11), 1004-1013 (2011).

4 Wang S, Ghosh AK, Bongio N et al. Fighting malaria with engineered symbiotic bacteria from vector mosquitoes. Proc. Natl Acad. Sci. USA 109(39), 12734-12739 (2012).

5 Chen CH, Huang H, Ward CM et al. A synthetic maternal-effect selfish genetic element drives population replacement in Drosophilia. Science 316(5824), 597-600 (2011).

6 Windbichler N, Menichelli M, Papathanos PA et al. A synthetic homing endonucleasebased gene drive system in the human malaria mosquito. Nature 473(7346), 212-215 (2011).

7 Roberts L. Battling over bed nets. Science 31(5850), 556-559 (2007).

8 Wells TNC, Alonso PL, Gutteridge WE. New medicines to improve control and contribute to the eradication of malaria. Nat. Rev. Drug Discov. 8(11), 879-891 (2009)

9 Wu T, Nagle AS, Chatterjee AK. Road towards new antimalarials: overview of the strategies and their chemical progress. Curr. Med. Chem. 18(6), 853-871 (2011).

10 Snow RW, Guerra CA, Noor AM, Myint HY, Hay SI. The global distribution of clinical episodes of Plasmodium falciparum malaria. Nature 434(7030), 214-217 (2005).

11 Meister, S, Plouffe, Kuhen, KL, Bonamy, GM et al. Imaging of Plasmodium liver stages to drive next generation antimalarial drug discovery. Science 334(6061), 1372-1377 (2011).

12 Derbyshire, ER, Prudencio, M, Mota MM, Clardy J. Liver-stage malaria parasites vulnerable to diverse chemical scaffolds. Proc. Natl Acad. Sci. USA 109(22), 8511-8516 (2012).

13 Gamo FJ, Sanz, LM, Vidal J et al. Thousands of chemical starting points for antimalarial lead identification. Nature 465(7296), 305-312, (2010).

14 Plouffe D, Brinker A, McNamara C et al. In silico activity profiling reveals the mechanism of action of antimalarials discovered in a high-throughput screen. Proc. Natl Acad. Sci. USA 105(26), 9059-9064 (2008).

15 Guiguemde WA, Shelat, AA, Bouck, D et al. Chemical genetics of Plasmodium falciparum. Nature 465(7296), 311-315 (2010).

16 Smithson DC, Guiguemde WA, Guy KR. Antimalarials. In: Burger's Medicinal Chemistry and Drug Discovery. John Wiley and Sons, Inc., New York, NY, USA (2010).

17 Nathan C. Making space for anti-infective drug discovery. Cell Host Microbe 9(5), 343-347 (2011).

18 Schreiber SL. Target-oriented and diversityoriented organic synthesis in drug discovery. Science 287(5460), 1964-1969 (2000).

19 Burke MD, Schreiber SL. A planning strategy for diversity-oriented synthesis. Angew. Chem. Int. Ed. 43(1), 46-58 (2004).

20 Neilson TE, Schreiber SL. Towards the optimal screening collection: a synthesis strategy. Angew. Chem. Int. Ed. 47(1), 48-56 (2007).

21 Galloway WRJD, Isidro-Llobet A, Spring DR. Diversity-oriented synthesis as a tool for the discovery of novel biologically active small molecules. Nat. Commun. 1(80), 1-13 (2010).

22 Dandapani S, Marcaurelle LA. Accessing new chemical space for 'undruggable' targets. Nat. Chem. Bio. 6(12), 861-863 (2010).

23 Payne DJ, Gwynn MN, Holmes DJ, Pompliano DL. Drugs for bad bugs: confronting the challenges of antibacterial discovery. Nat. Rev. Drug Discov. 6(1), 29-40 (2007).

24 Lovering F, Bikker J, Humblet C. Escape from flatland: increasing saturation as an approach to improving clinical success. J. Med. Chem. 52(21), 6752-6756 (2009).

25 Luker T, Alcaraz L, Chohan KK et al. Strategies to improve in vivo toxicology outcomes for basic candidate drug molecules. Bio. Med. Chem. Lett. 21(19), 5673-5679 (2011).

26 Smith AB III, Han H, Kim W-S. Diversityoriented synthesis of 2,4,6-trisubstituted piperidines via type ii anion relay chemistry. Org. Lett. 13(13), 3328-3331 (2011).

27 Lowe JT, Lee MD 4th, Akella LB et al. Synthesis and profiling of a diverse collection of azetidine-based scaffolds for the development of CNS-focused lead-like libraries. J. Org. Chem. 77(17), 7187-7211 (2012).

28 Fitzgerald ME, Mulroney CA, Duvall JR et al. Build/couple/pair strategy for the synthesis of stereochemically diverse macrolactams via head-to-tail cyclization. ACS Comb. Sci. 14(2), 89-96 (2012).
29 O'Connell KMG, Beckman HS, Laraia L et al. A two-directional strategy for the diversity-oriented synthesis of macrocyclic scaffolds. Org. Biomol. Chem. 10(37), 7545-7551 (2012).

30 Samarakoon TB, Loh JK, Rolfe A et al. A modular reaction pairing approach to the diversity-oriented synthesis of fused-and bridged-polycyclic sultams. Org. Lett. 13(19), 5148-5151 (2011).

31 Valot G, Garcia J, Duplan V et al. Diversityoriented synthesis of diverse polycyclic scaffolds inspired by the logic of sesquiterpene lactones biosynthesis. Angew. Chem. Int. Ed. 51(22), 5391-5394 (2012).

32 Zhang QS, Lu HJ, Richard C, Curran DP. Fluorous mixture synthesis of stereoisomer libraries: total syntheses of (+)-murisolin and fifteen diastereoisomers. J. Am. Chem. Soc. 126(1), 36-37 (2004).

33 Wrona IE, Lowe JT, Turbyville TJ et al. Synthesis of a 35-member stereoisomer library of bistramide A: evaluation of effects on actin state, cell cycle and tumor cell growth. J. Org. Chem. 74(5), 1897-1916 (2008).

34 Heidebrecht RW Jr, Mulrooney C, Austin $\mathrm{CP}$ et al. Diversity-oriented synthesis yields a novel lead for the treatment of malaria. ACS Med. Chem. Lett. 3(2), 112-117, (2012).

35 Marcaurelle LA, Comer E, Dandapani S et al. An aldol-based build/couple/pair strategy for the synthesis of medium- and large-sized rings: discovery of macrocyclic histone deacetylase inhibitors. J. Am. Chem. Soc. 132(47), 16962-16976 (2010).

36 Rottmann M, McMamara C, Yueng BK et al. Spiroindolones, a potent compound class for the treatment of malaria. Science 329(5996), 1175-1180 (2010).

37 Yeung BKS, Rottmann M, Lakshminarayana SB et al. Spirotetrahydro $\beta$-carbolines spiroindolones): a new class of potent and orally efficacious compounds for the treatment of malaria. J. Med. Chem. 53(14), 5155-5164 (2010).

38 Brown LE, Cheng KC-C, Wei W-G et al. Discovery of new antimalarial chemotypes through chemical methodology and library development. Proc. Natl Acad. Sci. USA 108(17), 6775-6780 (2011).

39 Sauer WH, Schwarz MK. Molecular shape diversity of combinatorial libraries: a prerequisite for broad activity. J. Chem. Inf. Comput. Sci. 43(3), 987-1003 (2003).

40 Lou S, Taoka BM, Ting A, Schaus SE. Asymmetric Mannich reactions of $\beta$-keto esters with acyl imines catalyzed by cinchona alkaloids. J. Am. Chem. Soc. 127(32), 11256-11257 (2005). 
41 Lou S, Dai P, Schaus SE. Asymmetric Mannich reaction of dicarbonyl compounds with $\alpha$-amido sulfones catalyzed by cinchona alkaloids and synthesis of chiral

dihydropyrimidones. J. Org. Chem. 72(26), 9998-10008 (2007).
42 Beeler AB, Su S, Singleton CA, Porco JA Jr. Discovery of chemical reactions through multidimensional screening. J. Am. Chem. Soc. 129(5), 1413-1419 (2007).

43 Joy DA. Early origin and recent expansion of Plasmodium falciparum. Science 300 (5617) 318-321 (2003).

\section{- Websites}

101 WHO: ten facts on malaria. www.who.int/features/factfiles/malaria/en/ index.html

102 Centers for disease control and prevention: insecticide-treated bed nets. www.cdc.gov/malaria/malaria_worldwide/ reduction/itn.html 